\section{INFLUENCE OF WATER-CEMENT RATIO AND WATER REDUCING ADMIXTURES ON THE REBOUND NUMBER OF HARDENED CONCRETE}

\author{
Kolawole Adisa Olonade \\ Department of Civil and Environmental Engineering Faculty of \\ Engineering, University of Lagos, Akoka, Nigeria
}

Article history

Received

30 May 2020

Received in revised form

13 September 2020

Accepted

21 October 2020

Published online

30 November 2020

*Corresponding author kolonade@unilag.edu.ng

\begin{abstract}
In this paper, effect of water-cement ratio $(\mathrm{w} / \mathrm{c}$ ) and type of water reducing admixtures (WRA) on the Schmidt hammer rebound number (RN) were investigated. Concrete of mix ratio 1:2:4 was prepared at the w/c of $0.45,0.50,0.55$ and 0.60 and with each of the three WRA at the w/c of 0.45 . Concrete cubes of size $150 \mathrm{~mm}$ were cast and cured in water for 3, 7 and 28 days. RNs of the cubes were determined and the compressive strengths $\left(f_{c}\right)$ corresponding to the RNs obtained from the conversion graph supplied by the manufacturer were compared with the compressive strengths obtained from crushing machine (CM). The results showed that as the w/c increased, the RN increased up to when w/c was 0.5 and began to drop, while there was no significant effect of all the WRA on the RN. It was also found that $f_{c}$ obtained from CM and those obtained using the conversion graph differed considerably. A new correlation graph was therefore proposed, which showed a correlation coefficient of 0.96 , while coefficient of determination obtained for the regression equation between $R N$ and $f_{c}$, was as high as 0.92 . The study concluded that $w / c$ had effect on $R N$ and that the equation developed could be used to determine $f_{c}$, once $R N$ is known.
\end{abstract}

Keywords: Rebound number, water reducing admixture, compressive strength, water-cement ratio, correlation.

\subsection{INTRODUCTION}

The frequency at which concrete structures collapse in most developing countries, especially Nigeria, has been a major concern for all stakeholders. In order to forestall a repeat of such preventable disasters, most old concrete structures are subjected to structural integrity assessment to be able to determine their fitness for use. In another situation, when additional storey is to be put on an existing building, there is always need to ascertain the capability of the existing structure to carry or accommodate the new storey. Also, where a concrete structure has been abandoned for a long period and there is need to resume construction, structural integrity of the structure would be required to determine its residual strength. It could also be required as routine check for the purpose of maintenance. Similarly, it could be deployed to settle rifts between contractors and consultants over quality of concrete used. In any of these cases, non-destructive testing (NDT) remains the major technique to adopt.

Originally, NDT was developed for inspection of metals and pipelines to identify defects in steel. With this application, recognized national and international standards have been developed. Its use in concrete inspection was lately developed due to heterogeneous nature of concrete with varying constituents [1].

In the recent past, quite a number of techniques have been developed to monitor concrete performance. Of these techniques, Rebound Hammer (RH) otherwise known as Schmidt Hammer (SH) becomes more popular due to its simplicity of use and possibly less cost [2]. There are different types of $\mathrm{SH}$ that have been developed, depending on the impact energy. Common ones are $\mathrm{L}$ and $\mathrm{N}$ types, but the re are no clear guidelines on what determine the choice of the type to use. While some standards specify a particular type of SH for use, quite a number of them did not specify hammer type, indicating that the type of hammer may not influence the results [3].

This technique, $\mathrm{SH}$, measures the rebound number that is observed, when the plunger is pushed against a hard surface [4]. The rebound number (RN) measured could be a good representation of compressive strength of concrete, if size able numbers of points are measured in a grid [3]. Now, national and international standards have been developed for its use [ 4 - 6]. A considerable amount of literature has been published on the practical use of $\mathrm{SH}$. These studies seem to assess the 
reliability of SH for determining in-place concrete quality, when compared with the traditional method of crushing test.

Sanchez and Tarranza [7] used SH to assess compressive strength of existing structure and compared their results with crushing test; it was found that SH test was comparable to crushing test. In a similar study conducted by [8] on series of laboratory tests, the compressive strength obtained from $\mathrm{SH}$ was marginally higher than that of crushing test by about $1.6 \%$, which shows a high level of reliability of the technique. Strengths obtained from SH and Ultrasonic Pulse Velocity (UPV) were found to be comparable to what was obtained from crushing test. However, combining the SH and UPV tests would give more accurate estimation of compressive strength of inplace concrete [9]. Brozovsky [10] also monitored the strength of brick, using $\mathrm{SH}$ and obtained fairly reliable results, while [11] employed the technique to monitor strength development of concrete containing copper slag (CS) as fine aggregate. The results indicated that $\mathrm{SH}$ technique mirrors the strength development as CS content varied, when compared with crushing method. Apart from using $\mathrm{SH}$ in testing concrete quality, the method is also being used extensively to determine uniaxial strength of rock [12]. It has also been used as dating tool in archeological sciences [13].

One major challenge with the use of $\mathrm{SH}$ is finding appropriate correlation that will convert $\mathrm{RN}$ obtained from $\mathrm{SH}$ to compressive strength. Though, the manufacturer of SH often provides conversion curves, yet there have been strong criticisms as to the extent the curve can mimic all the factors affecting concrete strength. This is recognized by [4], when it recommends that users should develop a correlation for the device used on the concrete mixture to be tested, for more reliable results. Another limitation of the correlation given by the manufacturer is that surfaces that have low RN could not be used to estimate strength. This is because the relationship between hardness and concrete strength depends on factors affecting the concrete surface such as saturation degree, temperature, carbonation, surface preparation and direction of testing [14]. Other factors that have been identified to have influence on the SH test include size of the specimen [15], aggregate type [16], type of cement [17]. In similar trend, Yasar and Erdogan [18] showed that $\mathrm{SH}$, rebound number reduced with increase in porosity and they developed an empirical equation, while [19] established a correlation between RN and density of the material.
Despite extensive literature on the role water-cement ratio $(\mathrm{w} / \mathrm{c})$ and chemical admixtures play on the mechanical and durability properties of concrete, the effect of both on the RN of $\mathrm{SH}$ of hardened concrete is still very unclear. In this study, therefore, attempt was made to establish influence of $\mathrm{w} / \mathrm{c}$ and selected WRA on the RN of SH. An empirical function bet we e $n$ the $\mathrm{RN}$ and w/c was developed, while correlation between the strength determined from $\mathrm{SH}$ and crushing test was equally established. The findings from this study should make an important contribution to the field of NDT.

\subsection{MATERIALS AND METHODS}

\subsection{Materials}

The cement used for this research work was Elephant cement (ordinary Portland cement). Sand of maximum nominal size of $3.35 \mathrm{~mm}$ and granite of maximum size of $18 \mathrm{~mm}$ were used as fine and coarse aggregates, respectively. Potable water was used for mixing, while WRAs used were plasticizers of brand names Rheobuild 850 and Mapaei NS100 and a superplasticizer, Meflux 101F.

\subsection{Concrete Mixing and Casting}

Concrete specimen used was batched by weight with mix ratio of 1:2:4 (cement: sand: granite) and varied water cement ratio at with dosage of superplasticizer. For assessing effect of $w / c$, different $w / c$ ranging from 0.45 to 0.60 at intervals of 0.05 were studied, without WRAs. In the other concrete specimen $\mathrm{s}$, different WRAs were used at constant $w / c$ of 0.45 . Each WRAs was added to the concrete mix separately at average dosage recommended by their manufacturers. Specifically, the dosage used for every $50 \mathrm{~kg}$ of cement was $425.53 \mathrm{ml}$ of Rhe obuild, $531.91 \mathrm{ml}$ of Mapaei NS100 and $262.5 \mathrm{~g}$ of Meflux 101F. The choice of fixed $w / c$ of 0.45 was based preliminary study. In all, seven different concrete specimens were produced (S1 to S7). For instance, S1 was made with w/c of 0.45 without WRA, while S6 was made with $\mathrm{w} / \mathrm{c}$ of 0.45 and Mapaei NS100. Table 1 summarizes the material constituents per cubic metre of each concrete specimen produced for this study.

Table 1 Concrete mix composition and sample identification

\begin{tabular}{lrrrrrrr}
\hline Materials & \multicolumn{7}{c}{ Concrete Specimen Identification } \\
\cline { 2 - 9 } & \multicolumn{1}{c}{ S1 } & \multicolumn{1}{c}{ S2 } & \multicolumn{1}{c}{ S3 } & \multicolumn{1}{c}{ S4 } & \multicolumn{1}{c}{ S5 } & \multicolumn{1}{c}{ S6 } & \multicolumn{1}{c}{ S7 } \\
\hline Cement (kg) & 336.7 & 331.0 & 325.5 & 320.2 & 331.0 & 331.0 & 331.0 \\
Sand (kg) & 673.4 & 662.0 & 651.0 & 640.4 & 662.0 & 662.0 & 662.0 \\
Granite (kg) & 1346.8 & 1324.1 & 1302.1 & 1280.8 & 1324.1 & 1324.1 & 1324.1 \\
Water (kg) & 134.7 & 149.0 & 162.8 & 176.1 & 149.0 & 149.0 & 149.0 \\
Rheobuild (lit.) & - & - & - & - & 2.8 & - & - \\
Mapaei NS100 (lit.) & - & - & - & - & - & 3.5 & - \\
Meflux 101F (kg) & - & - & - & - & - & - & 1.7 \\
Water/cement ratio & 0.45 & 0.50 & 0.55 & 0.6 & 0.45 & 0.45 & 0.45 \\
\hline
\end{tabular}


Prior to casting the concrete specimens into steel moulds of sizes $150 \times 150 \times 150 \mathrm{~mm}$, slump test was carried out on the fresh concrete. Finally, six concrete cubes were cast for each concrete specimen, three samples each for $\mathrm{SH}$ test and crushing test. The moulds and their contents were covered with polythene bags to prevent loss of moisture for 24 hours. Thereafter, the concrete cubes were removed from the moulds and immersed in water for curing until the test dates of 3,7 and 28 days.

\subsection{Methods}

\subsubsection{Material characterization}

Chemical composition of the cement was determined using $\mathrm{XRF}$, while its physical properties such as specific gravity (sg) and those of the aggregates were determined along with si e ve analysis based on the provisions of [20]. Particle size distribution curves were plotted and grading coefficients (coefficients of curvature, $C_{c}$ and uniformity, $C_{u}$ ) determined based on the equations provided by [21] and reproduced here as Equations (1) and (2).

$$
\begin{aligned}
& C u=D 10 / D 60 \\
& C c=(D 30) 2 /(D 10 x D 60)
\end{aligned}
$$

Where $D_{10}, D_{30}$ and $D_{60}$ are diameters of the soil particle for which, 10, 30 and 60 percent of the particles are finer, respectively.

\subsubsection{Slump, Compressive strength and SH Rebound Number}

The only workability test performed on the fresh concrete mixes was slump test. This test was carried out according to [22]. As earlier mentioned, three cube samples from each concrete specimen were tested for compressive strength using crushing method in accordance with the provision of [23]. This was carried out at the ages of 3,7 and 28 days. Average of the three readings was determined. Prior to crushing, the concrete cubes were weighed and sizes were measured for the determination of density. Rebound numbers were determined using the remaining three cubes. Each cube was gridded as shown in Figure 1 (a) and the plunger of the $\mathrm{SH}$ was held vertically downward and used to hit each point on the specimen (Figure 1b). Thereafter the RN was read on the machine. N-Type of SH was used. The procedure highlighted in [5] were followed. Nine (9) points were tested on each cube making the total RN obtained from each concre te sample to be twenty-seven (27). Thereafter, outliers were determined using Chauvenet's criterion [24]. Average of the remaining values, after rejecting outliers, were then determined as long as the total readings were not less than 18 , else more testing would be needed [5].

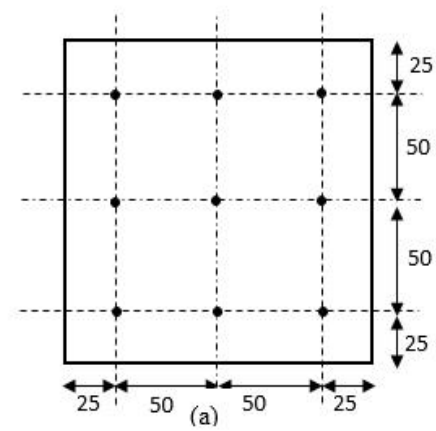

All dimensions in $\mathrm{mm}$

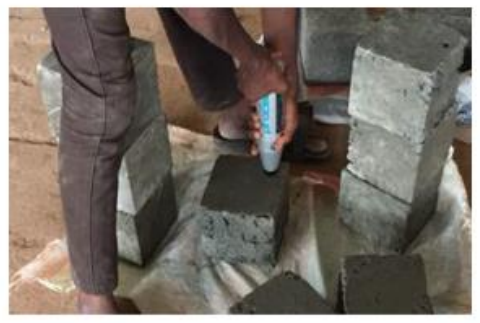

(b)

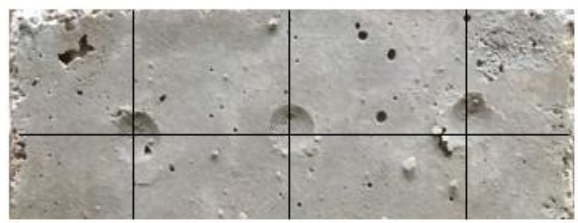

(c)

Figure 1: Specimen preparation and testing (a) Position on concrete cubes where RN were taken ( 9 points per cube) (b) direction of the hammer to the concrete specimen (Vertical Downward) (c) Indentation of concrete sample at 3 and 7 days after testing.

\subsection{Analysis of data}

During the testing, huge data were collected and the data was subjected to statistical analysis. Two statistical approaches were used to analyze and draw conclusion from the data collected. Microsoft Excel 2016 software package was use d for the analysis. Descriptive statistics was carried out with a view to determining mean values and standard deviation to be able to understand the consistence and spread of the data collected. The study also used inferential statistics on the data collected in order to model patterns in the data, account for randomness and draw inferences. The inferences considered were correlation and regression. While correlation describes association of data, regression models the relationship. From the data, correlation was carried out between strengths obtained from $\mathrm{SH}$ and those obtained from crushing method, while models relating strength and other variables such as $\mathrm{RN}$, $\mathrm{w} / \mathrm{c}$ and ages were formulated. The population regression model was simulated and the empirical function that gave highest R-square value was taken as the best goodness-of-fit measure. Aydin and Basu [19] also used similar approach. 


\subsection{RESULTS AND DISCUSSION}

\subsection{Properties of materials}

The oxide composition of the Portland cement used as determined from XRF technique is presented in Table 2 . The cement contained expected oxides in quantities that fell within the limit stipulated by BS EN 196 - 2 (2013) for cement to be categorized as CEM I. However, the $\mathrm{CaO}$ content was found to be slightly lower than recommended minimum value of $61 \%$. This decrease is insignificant to make the cement unfit for use. The slight reduction in the $\mathrm{CaO}$ content may either be due to the source of raw materials from which the cement was produced, or handling during production process. The mineral composition of the ce ment (\% mass) as estimated from Bogue's Equation [25] were
55.89\% $\left(\mathrm{C}_{3} \mathrm{~S}\right), 12.01\left(\mathrm{C}_{2} \mathrm{~S}\right), 6.18\left(\mathrm{C}_{3} \mathrm{~A}\right)$ and $7.24\left(\mathrm{C}_{4} \mathrm{AF}\right)$. The minerals were also within the acceptable limit [25].

Table 3 summarizes the properties of the aggregates used, while their particle size distribution curves are presented in Figure 2 . The aggregates are classified as normal weight aggregates as their densities fell within the limits provided by [23]. Similarly, using the criteria of the standard, the aggregates were well graded and were accepted for concrete production as they met the minimum requirements. Thus, it could be deduced that the materials were appropriate for making normal weight concrete. For the gradation characteristics of the aggregates, it was observed that more than $90 \%$ of sand passed the sieve No. 4 $(4.75 \mathrm{~mm})$ while less than $5 \%$ were retained on sieve No. 200. The coefficients of curvature $\left(C_{c}\right)$ of sand and granite were 1.6 and 1.3 respectively, while the corresponding coefficients of uniformity were 10 and 4.4 (Table 3 ). They were all within the acceptable limits.

Table 2 Chemical and physical properties of OPC

\begin{tabular}{|c|c|c|c|c|c|c|c|c|c|c|c|c|}
\hline \multirow[t]{2}{*}{ Material } & \multicolumn{10}{|c|}{ Oxides (\%) } & \multirow[t]{2}{*}{ LOI } & \multirow{2}{*}{$\begin{array}{l}\text { Specific } \\
\text { gravity }\end{array}$} \\
\hline & $\mathrm{SiO}_{2}$ & $\mathrm{Al}_{2} \mathrm{O}_{3}$ & $\mathrm{Fe}_{2} \mathrm{O}_{3}$ & $\mathrm{CaO}$ & MgO & $\mathrm{SO}_{3}$ & $\mathrm{Na}_{2} \mathrm{O}$ & $\mathrm{K}_{2} \mathrm{O}$ & $\mathrm{TiO}_{2}$ & $\mathrm{P}_{2} \mathrm{O}_{5}$ & & \\
\hline OPC & 18.89 & 3.85 & 2.38 & 58.45 & 1.54 & 1.76 & 0.10 & 0.24 & 0.20 & 0.31 & 9.80 & 3.09 \\
\hline
\end{tabular}

Table 3 Physical properties and grading coefficients of aggregates

\begin{tabular}{lrrr}
\hline Properties & \multicolumn{2}{c}{ Aggregates } & Recommended Limits \\
\cline { 2 - 3 } & Sand & Granite & \\
\hline Specific Gravity & 2.67 & 2.76 & 2.30 to $2.90^{\mathrm{a}}$ \\
Bulk Density, $\mathrm{kg} / \mathrm{m}^{3}$ & 1530 & 1680 & 1280 to $1920^{\mathrm{a}}$ \\
Fineness Modulus & 2.83 & 6.59 & $2-3.4^{\mathrm{a}^{*}}$ \\
Coefficient of Curvature, $C_{\mathrm{E}}$ & 1.60 & 1.30 & $1-3^{\mathrm{b}}$ \\
Coefficient of Uniformity, $C_{\text {wis }}$ & 10.00 & 4.40 & $>4^{\mathrm{b}}$ \\
\hline
\end{tabular}

${ }^{*}$ Fineness Modulus for fine aggregate; a ASTM C33; ${ }^{\text {b }}$ Peck et al (1974)

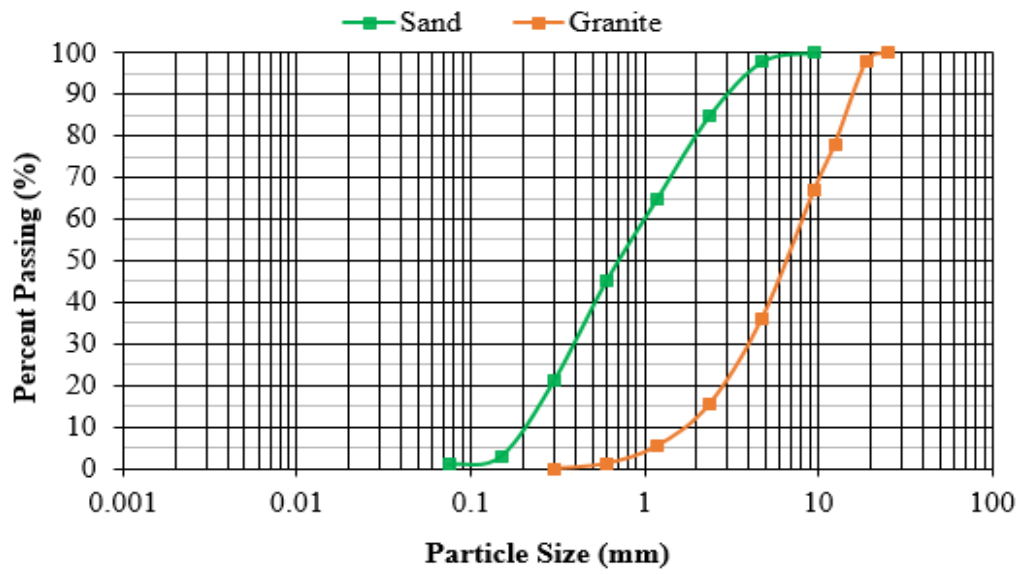

Figure 2: Particle size distribution curves of aggregates

\subsection{Effect of $w / c$ and SP on workability}

Table 4 shows the slump values obtained for the concrete specimens. At $w / c$ of 0.45 the slump value was as small as 5 $\mathrm{mm}$, indicating that the concrete was stiff and would be difficult to fill formwork, difficult to pump as well as hard to compact. Honeycombs and porosity are characteristics of this type of concrete and durability challenges as well as I ow strength [26]. Similarly, the consistence is outside the consistence classes given by BS EN 206-1 (2000). With successive increase in $\mathrm{w} / \mathrm{c}$ to 0.5 and 0.55 , slump moved further about $300 \%$ and $500 \%$ of initial slump at $w / c$ of 0.45 , respectively. At higher $w / c$ value of 0.6 , the slump was 90 $\mathrm{mm}$, representing 16 times the initial slump. Increase in slump was equally observed when the admixtures were added but more pronounced with the presence of Meflux $101 \mathrm{~F}$. Its slump was twice the slump of Mapaei NS100 and about one and half of that of Rheobuild. Though performance of Meflux 101F may not be surprising, because it belongs to the class of superplasticizer while other admixtures (Rheobuild and Mapaie) were plasticizers. According to [25], superplasticizers have the potential to increase slump to about $150 \mathrm{~mm}$ depending on the dosage, initial slump of concrete, cement content and type; while 
plasticizers can increase slump to about $80 \mathrm{~mm}$. With admixtures, concrete specimen $\mathrm{S} 1$ becomes more workable with possibility of low porosity, which subsequently increased the strength. This effect is shown in the high er RN obtained as discussed in the next section.

Table 4 Effect of $w / c$ and Admixtures on slump values of concrete specimen

\begin{tabular}{lcccccccc}
\hline Property & \multicolumn{4}{c}{ w/c } & & \multicolumn{3}{c}{ SP } \\
\cline { 2 - 4 } \cline { 8 - 9 } & $\mathbf{0 . 4 5}$ & $\mathbf{0 . 5}$ & $\mathbf{0 . 5 5}$ & $\mathbf{0 . 6}$ & & Rheobuild & Mapaei NS100 & Meflux 101F \\
\hline Slump (mm) & 5 & 20 & 30 & 80 & & 70 & 50 & 105 \\
\hline
\end{tabular}

\subsection{Effect of WRA type and water cement ratio on RN}

Table 5 shows the RN obtained from each of the concrete samples studied at different ages. The RN was found to be increasing with age for all the mixes, as shown by their average values. At the curing ages of 3 and 7 days, low RN were obtained for all the samples but more pronounced in Samples S1, S4 and S7. In fact, surface depressions were noticed on the surfaces of the concrete samples, indicating that the surfaces were still very weak (Figure 1c). However, as the age of the concrete increased to 28 days, relative hard surfaces were obtained, so the RN numbers increased. It is known that as the age increases, more stable hydration products, such as calcium silicate (CSH) and calcium aluminate hydrate (CAH) that contribute to increase in strength are formed, making the surfaces harder. Regarding the effect of $w / c$ on the RN, at lower $w / c(0.45)$ as well as at higher $w / c$ of 0.6 the RN declined compared to the values obtained at $w / c$ of 0.5 and 0.55 . Sample S1 could be said to have more porous zones due to lack of enough water to enhance flow of the concrete; and the low RN may be attributed to this. In the case of Sample $S 4(w / c=0.6)$, the higher $w / c$ may result in interconnection of pore structure within the hydrates, causing weaker concrete. On the other hand, the available water may be too much above what is required for hydration. Therefore, residual water in the concrete mix may create weak zones, which could be responsible for low RN (Table 5). Nevertheless, two outliers were recorded during testing of Sample S1. It was possible that the hammer hit the porous section and lower RN of 7 was obtained, while higher value of 17 recorded may be that the hammer hit the zone where coarse aggregates clustered. This result indicated that porous sample had low RN as found in Sample S1, which is line with what Yasar and Erdogan (2004) reported in their work. Relative higher RN values obtained for Samples S2 (w/c = 0.5) and S3 (w/c=0.55), $\mathrm{might}$ be that the water was used up for hydration reaction in one part and could be that they were adequate to produce consistence concrete as shown by their slump values (Table 4).

In the case of other samples ( $\mathrm{S} 5, \mathrm{~S} 6$ and $\mathrm{S7}$ ), there were no difference in the average RNs obtained (Figure 3). Nevertheless, they had higher RN than concrete S1 at w/c of 0.45 . These results suggested that the presence of plasticizers would make concrete more workable and possibly reduced porosity that characterized Sample S1. At ages 3 and 7 days, however, the RN of S1 was comparable to those of Samples S5 to S7. This may be due to delay in hydration reaction, due to the presence of plasticizers [27].
Effect of $w / c$ on $R N$ of the concrete specimens was also studied, using statistical analysis. The results indicated that the effect of water/cement ratio was significant, $F(1,530)=$ $58.435, p<.05$. From the estimated marginal means, the $R N$ made significantly more errors in the $w / c=0.5(M=19.409)$ and $0.55(\mathrm{M}=17.321)$ than in the $\mathrm{w} / \mathrm{c}$ of $0.45(\mathrm{M}=16.467)$ and $0.6(M=15.148)$. Similarly, Age of curing also had significant effect on the $R N, F(1,531)=997.499, p<0.05$. From the estimated marginal means, there were more significant errors at age 28 days $(M=22.417)$ compared to age 3 days $(M=11.424)$ and age 7 days $(M=16.622)$. However, WRAs seemed not to have significant effect on RN, $F(1,531)=1.699, p>0.05$. The difference in the number of errors made by the Rheobuild ( $M=16.566$ ) is not significantly different from the number of errors made by Mapaei NS100 $(M=16.835)$ and Meflux 101F ( $M=16.381)$.

Furthermore, interaction of age and water/cement ratio, as well as age and WRAs, equally had significant effects on RN $(P<0.05)$, while there were no interactions between water-cement ratio and plasticizer because there were $n o p$ values for the interaction. This is so, because only w/c of 0.45 was used with WRAs. Nevertheless, effect of the interaction between $\mathrm{w} / \mathrm{c}$ and WRA could be a subject of future study.

\subsection{Correlation between compressive strength for SH and Crushing Test}

Table 6 contains the compressive strengths obtained from RN using the conversion graphs and the compressive strengths obtained from the crushing test. For ages 3 and 7, the average RNs were less than 20 and as such there were no equivalent strength for them on the conversion graphs provided by the SH's manufacturer. This situation seems to be one of the limitations of $\mathrm{SH}$ in assessing strength of concrete element that has lower surface hardness with RN less than 20. Whereas there were values for strengths measured from crushing test. Thus, SH could not be used to determine the early strengths of the concrete mixes. Hence, empirical relations between $\mathrm{RN}$ and the compressive strength of concrete become imperative for effective use of $\mathrm{SH}$ for assessing the compressive strength of concrete structure at any age.

Nevertheless, correlation analysis suggested that there was a positive correlation between the strengths obtained from $\mathrm{SH}$ and the corresponding strengths obtained from the crushing test and was statistically significant $(r=0.967, p<$ 0.01 ). The significant relationship indicated the $\mathrm{SH}$ seem to give indication of the strength of the concrete specimen, though it may not give precise strength, as found from this study. 
Table $5 \mathrm{RN}$ of concrete specimens at different ages

\begin{tabular}{|c|c|c|c|c|c|c|c|c|c|c|c|c|c|c|c|c|c|c|c|c|c|}
\hline \multirow{4}{*}{$S / N$} & \multicolumn{21}{|c|}{ Rebound Numbers } \\
\hline & \multicolumn{3}{|c|}{$\mathrm{S} 1(\mathrm{w} / \mathrm{c}=0.45)$} & \multicolumn{3}{|c|}{$\mathrm{S} 2(\mathrm{w} / \mathrm{c}=0.50)$} & \multicolumn{3}{|c|}{$\mathrm{S3}(\mathrm{w} / \mathrm{c}=0.55)$} & \multicolumn{3}{|c|}{$S 4(w / c=0.60)$} & \multicolumn{3}{|c|}{ S5 (Rheobuild) } & \multicolumn{3}{|c|}{ S6 (Mapaei NS100) } & \multicolumn{3}{|c|}{ S7 (Meflux 101F) } \\
\hline & \multicolumn{3}{|c|}{ Day } & \multicolumn{3}{|c|}{ Day } & \multicolumn{3}{|c|}{ Day } & \multicolumn{3}{|c|}{ Day } & \multicolumn{3}{|c|}{ Day } & \multicolumn{3}{|c|}{ Day } & \multicolumn{3}{|c|}{ Day } \\
\hline & 3 & 7 & 28 & 3 & 7 & 28 & 3 & 7 & 28 & 3 & 7 & 28 & 3 & 7 & 28 & 3 & 7 & 28 & 3 & 7 & 28 \\
\hline 1 & 9 & 16 & 18 & 10 & $11^{*}$ & 29 & 10 & 19 & 22 & 10 & 15 & 24 & 9 & 20 & 22 & 10 & 21 & 22 & 12 & 22 & 20 \\
\hline 2 & 13 & 18 & 25 & $5^{*}$ & 19 & 28 & 12 & 15 & 23 & 12 & 17 & 20 & 10 & 22 & 21 & 11 & 22 & 22 & 9 & 19 & 23 \\
\hline 3 & 12 & 19 & 23 & 10 & 18 & 26 & 11 & 18 & 24 & 11 & 15 & 19 & 11 & 21 & 23 & 11 & 19 & 22 & 11 & 17 & 21 \\
\hline 4 & 12 & 20 & 21 & 14 & 17 & 30 & 10 & 13 & 23 & 10 & 24 & 21 & 10 & 20 & 20 & 10 & 20 & 22 & 10 & 20 & 22 \\
\hline 5 & 10 & 14 & 19 & 15 & 17 & $15^{*}$ & 11 & 20 & 25 & 10 & 12 & 21 & 11 & 16 & 20 & 11 & 14 & 22 & 11 & 14 & 24 \\
\hline 6 & 12 & 20 & 20 & 10 & 15 & 24 & 11 & 14 & 24 & 11 & 13 & 23 & 10 & 20 & 24 & 12 & 19 & 20 & 12 & 20 & 26 \\
\hline 7 & 12 & 15 & 21 & 14 & 23 & 32 & 10 & 16 & 25 & 12 & 17 & 23 & 12 & 15 & 25 & 10 & 15 & 20 & 10 & 15 & 23 \\
\hline 8 & 12 & 15 & 18 & 12 & 16 & 26 & 13 & 18 & 23 & 12 & 13 & 21 & 12 & 15 & 26 & 13 & 14 & 22 & 9 & 16 & 22 \\
\hline 9 & 10 & 14 & 20 & 16 & 19 & 23 & 12 & 12 & $29^{*}$ & 11 & 14 & 19 & 12 & 14 & 22 & 12 & 13 & 24 & 12 & 14 & 22 \\
\hline 10 & 14 & 15 & 18 & 14 & 19 & 28 & $16^{*}$ & 20 & 20 & 10 & 15 & 21 & 11 & 15 & 20 & 12 & 16 & 26 & 12 & 15 & 21 \\
\hline 11 & 13 & 16 & 23 & 10 & 15 & 25 & 11 & 16 & 20 & 10 & 14 & 19 & 8 & 16 & 26 & 11 & 16 & 24 & 11 & 16 & 21 \\
\hline 12 & 12 & 12 & 19 & 12 & 19 & 30 & 11 & 22 & 23 & 11 & 13 & 20 & 10 & 12 & 20 & 11 & 14 & 22 & 11 & 12 & 20 \\
\hline 13 & 12 & 17 & 17 & 12 & 15 & 30 & 10 & 13 & 26 & 10 & 12 & 15 & 12 & 17 & 23 & 10 & 17 & 23 & 10 & 17 & 20 \\
\hline 14 & 10 & 18 & 20 & 14 & 23 & 23 & 14 & 15 & 24 & 10 & 12 & 19 & 13 & 18 & 25 & 14 & 18 & 20 & 11 & 18 & $28^{*}$ \\
\hline 15 & $7^{*}$ & 19 & 23 & 16 & 21 & 27 & 10 & 20 & 24 & 11 & 10 & 16 & 10 & 19 & 21 & 10 & 19 & 20 & 10 & 19 & 20 \\
\hline 16 & 12 & 14 & 22 & $20^{*}$ & $26^{*}$ & 30 & 10 & 17 & 23 & 12 & 13 & 20 & 12 & 14 & 20 & 10 & 15 & 23 & 10 & 15 & 22 \\
\hline 17 & 15 & 20 & 18 & 10 & 19 & 23 & 13 & 21 & 20 & 12 & 17 & 18 & 13 & 20 & 22 & 13 & 19 & $30^{*}$ & 13 & 20 & 20 \\
\hline 18 & 11 & 20 & 17 & 12 & 17 & $38^{*}$ & 10 & 20 & 21 & 11 & 14 & 21 & $16^{*}$ & 20 & 23 & 10 & 20 & 24 & 10 & 20 & 20 \\
\hline 19 & 12 & 15 & $26^{*}$ & 14 & 20 & 28 & 11 & 18 & 25 & 10 & 13 & 19 & 11 & 15 & 22 & 11 & 15 & 23 & 11 & 15 & 22 \\
\hline 20 & 14 & 13 & 21 & 15 & 18 & 24 & 12 & 18 & 21 & 10 & 14 & 20 & 9 & 14 & 21 & 12 & 13 & 24 & 12 & 14 & 20 \\
\hline 21 & 10 & 17 & 18 & 13 & 15 & $14^{*}$ & 12 & 18 & 23 & 12 & 16 & 21 & 10 & 17 & 20 & 14 & 17 & 22 & 10 & 17 & 21 \\
\hline 22 & 12 & 12 & 19 & 12 & 19 & 24 & 12 & $25^{*}$ & 21 & 11 & 12 & 22 & 11 & 14 & 22 & 12 & 16 & 22 & 12 & 12 & 20 \\
\hline 23 & 11 & 16 & 20 & $5^{*}$ & 17 & 25 & 10 & 16 & 24 & 13 & 14 & 21 & 13 & 16 & 21 & 10 & 14 & 23 & 10 & 15 & 23 \\
\hline 24 & 12 & 16 & 18 & 12 & 19 & 24 & 15 & 21 & 24 & 10 & 16 & 19 & 12 & 16 & 23 & 10 & 16 & 22 & 9 & 16 & 24 \\
\hline 25 & 12 & 12 & 21 & 13 & 20 & 31 & 11 & 20 & 24 & 11 & 14 & 22 & 10 & 12 & 20 & 11 & 12 & 26 & 11 & 12 & 22 \\
\hline 26 & 12 & 18 & 21 & 10 & 21 & 32 & 11 & 14 & 26 & 12 & 15 & 21 & 12 & 18 & 20 & 11 & 18 & 24 & 11 & 16 & 24 \\
\hline 27 & $17^{*}$ & 16 & 21 & 12 & 23 & 28 & 13 & 20 & 23 & 10 & 15 & 18 & 9 & 16 & 24 & 13 & 16 & 24 & 13 & 17 & 26 \\
\hline
\end{tabular}

'Rejected as outlier by Chauvenet's criteria, not included in analysis, 


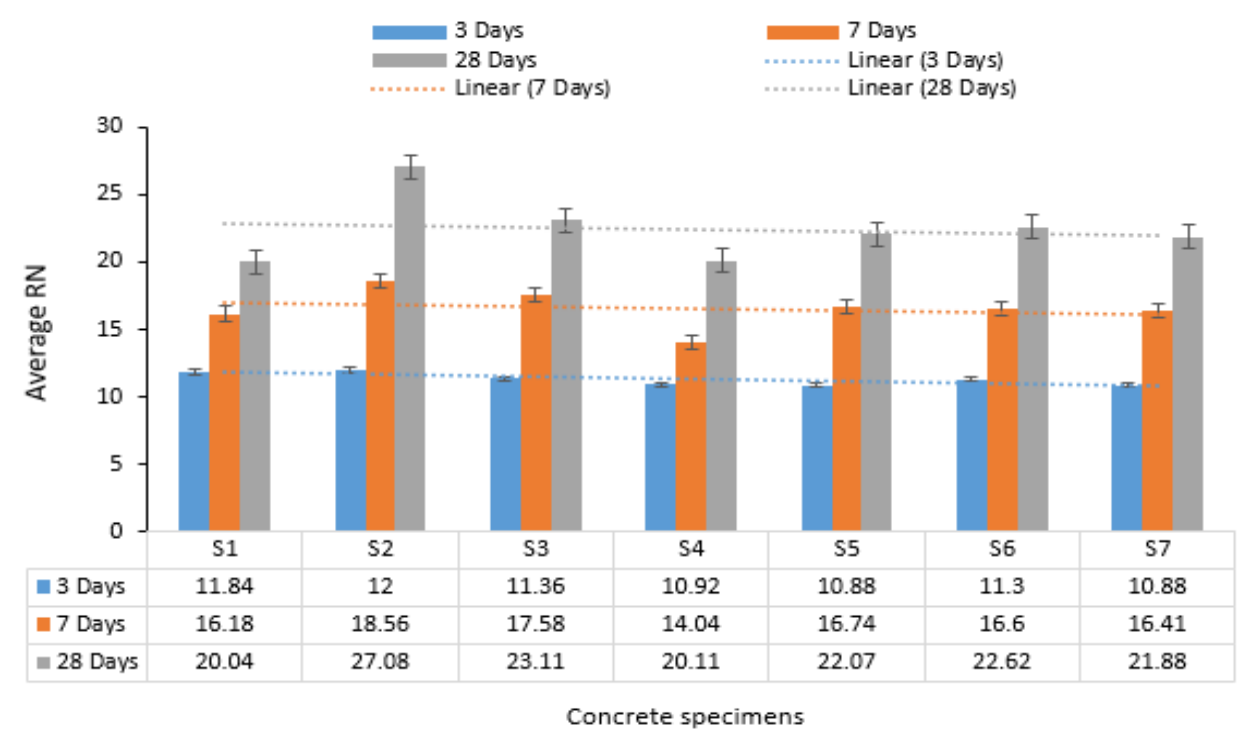

Figure 3 Average RN of concrete specimens

Table 6 RN and compressive strength of the concrete specimens at different curing ages

\begin{tabular}{|c|c|c|c|c|c|c|c|c|c|}
\hline \multirow{3}{*}{$\begin{array}{l}\text { Concrete } \\
\text { Specimen }\end{array}$} & \multicolumn{3}{|c|}{ Average RN } & \multicolumn{3}{|c|}{ Strength from $\mathrm{SH}\left(\mathrm{N} / \mathrm{mm}^{2}\right)$} & \multicolumn{3}{|c|}{ Strength from Crushing $\left(\mathrm{N} / \mathrm{mm}^{2}\right)$} \\
\hline & \multicolumn{3}{|c|}{ Curing Ages (Days) } & \multicolumn{3}{|c|}{ Curing Ages (Days) } & \multicolumn{3}{|c|}{ Curing Ages (Days) } \\
\hline & 3 & 7 & 28 & $3^{*}$ & $7^{*}$ & 28 & 3 & 7 & 28 \\
\hline$S 1(c / w=0.45)$ & 11.88 & 16.18 & 20.04 & - & - & 15.20 & 7.31 & 14.13 & 19.32 \\
\hline$S 2(c / w=0.50)$ & 12.00 & 18.56 & 27.08 & - & - & 25.50 & 10.23 & 17.39 & 27.85 \\
\hline$S 3(c / w=0.55)$ & 11.34 & 17.58 & 23.11 & - & - & 19.50 & 8.68 & 15.18 & 23.58 \\
\hline$S 4(c / w=0.60)$ & 10.92 & 14.04 & 20.11 & - & - & 15.50 & 7.13 & 15.26 & 21.47 \\
\hline S5 (Rheobuild) & 10.88 & 16.74 & 22.07 & - & - & 18.00 & 7.19 & 14.71 & 22.35 \\
\hline S6 (Mapaei NS100) & 11.30 & 16.60 & 22.62 & - & - & 18.50 & 9.97 & 13.23 & 22.12 \\
\hline S7 (Meflux 101F) & 10.88 & 16.41 & 21.88 & - & - & 16.73 & 8.74 & 12.67 & 20.32 \\
\hline
\end{tabular}

${ }^{*}$ There is no provision for strength at RN $<20$

\subsection{Regression Analysis}

\section{5. $1 \mathrm{RN}$ versus Ages and Water cement ratio}

Regression analysis was conducted on the RN data obtained taking $w / c(w)$ and ages $(t)$ as variables were carried out. Equations of the best-fit line (Equations 1-4) and the coefficient of determination ( $R$ ) were determined for each test results. It was found that non-linear equation (power equation) best represented the relationship between $\mathrm{RN}$ an $\mathrm{d}$ ages at a particular w/c (Figure 4). 


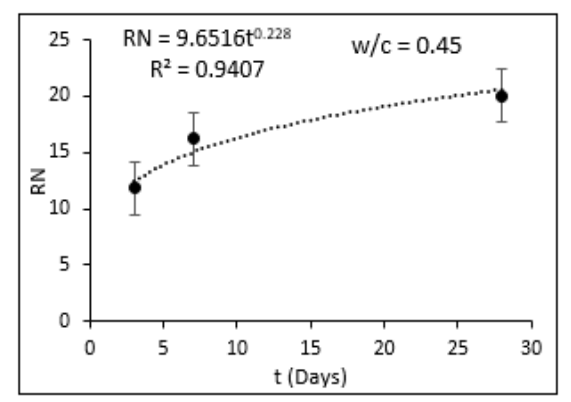

(a)

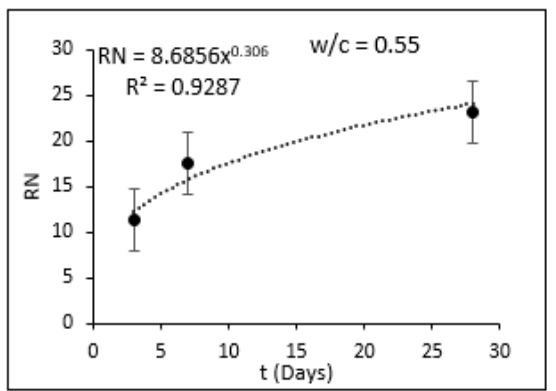

(c)

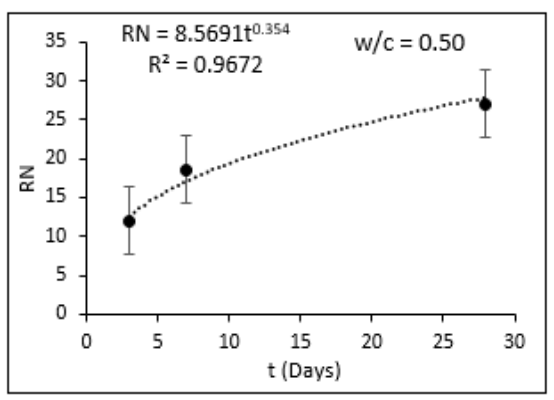

(b)

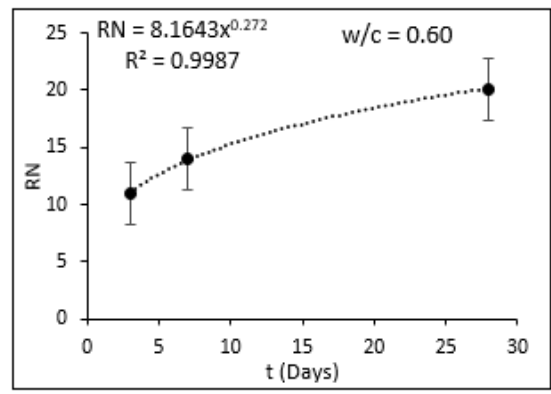

(d)

Figure 4 RN versus age of curing (t) at w/c of (a) 0.45 (b) 0.50 (c) 0.55 and (d) 0.60

The minimum $\mathrm{R}$-square value was 0.9287 , indicating that about $92.87 \%$ of the value of $R N$ is predicted by the value of curing age. The empirical relations are presented as Equations 3-6.

$$
\begin{aligned}
& \text { At } w / c=0.45, R N=9.6516 t^{0.228}\left(\mathrm{R}^{2}=0.94\right) \\
& \text { At } w / c=0.50, R N=8.5691 t^{0.354}\left(\mathrm{R}^{2}=0.97\right) \\
& \text { At } w / c=0.55, R N=8.6856 t^{0.305}\left(\mathrm{R}^{2}=0.93\right) \\
& \text { At } w / c=0.60, R N=8.1643 t^{0.272}\left(\mathrm{R}^{2}=0.99\right)
\end{aligned}
$$

Interestingly, the difference in the coefficients of the age (t) for all the w/c considered were not significantly different, suggesting that age of the concrete was a major factor influencing the value of RN. Nevertheless, to develop a full picture of effect of age and more exact empirical equations, there is need to consider more ages especially between 7 days and 28 days and/or beyond. Similar trend was observed, when RN was regressed with $w / c(w)$ at ages of 3 , 7 and 28 days (Figure 5) and the empirical relationships are represented as Equations 7-9. There were strong coefficients of determination between the $R N$ and $w / c(w)$ for all the equations, suggesting that the equations could be used to predict RN once $\mathrm{w} / \mathrm{c}$ is known for a particular age. 


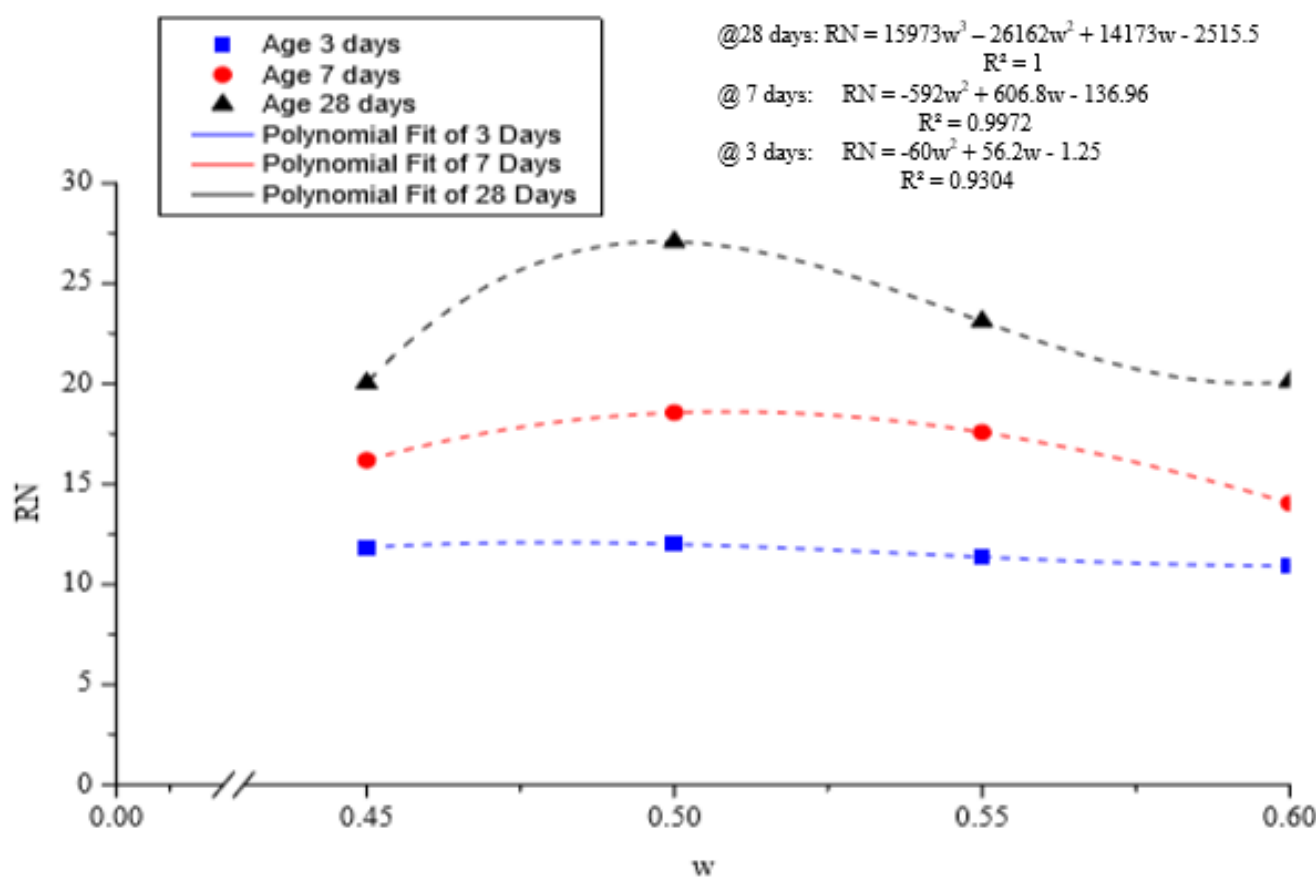

Figure 5 RN versus water-cement ratio (w)

$$
\begin{aligned}
& \text { At } 3 \text { days, } R N=-60 w^{2}+56.2 w-1.25 \quad\left(R^{2}=0.9304\right) \\
& \text { At } 7 \text { days: } R N=-592 w^{2}+606.8 w-136.96 \quad\left(R^{2}=0.9972\right) \\
& \text { At } 28 \text { days: } R N=15973 w^{3}-26162 w^{2}+14173 w-2515.5 \quad\left(R^{2}=1.000\right)
\end{aligned}
$$

Since both $w / c$ and age have been established to have significant impact on the value RN, regression analysis was equally conducted on the data with $\mathrm{RN}$ as dependent variable, while $w$ and $t$ were independent variable. The results showed that there was positive and strong correlation between $R N$ and the variables ( $t$ and $w)(R=0.911)$. Hence, both $t$ and $w$ have significant effect on the values of RN ( $p$
$<0.005)$. Furthermore, equation of the line of best-fit (Equation 10), has strong coefficient of determination $\left(\mathrm{R}^{2}=\right.$ 0.8301 ), indicating that $83 \%$ of the variation of the mean value of RN is determined by the combined interaction of age of the concrete $(t)$ and water-cement ratio $(w)$. Therefore, it could be safely concluded that the equation has predictive potential

for

$\mathrm{RN}$.

$$
R N=8 t^{0.3}-9.707 w+6.243 \quad\left(R^{2}=0.8302\right)
$$

\subsubsection{RN Versus Compressive Strength}

The main objective of carrying out $\mathrm{SH}$ test on concrete is to be able to determine the compressive strength of concrete. Though SH gives RN, which can be related to the hardness of the surface of concrete and further extended to compressive strength. This is achieved by establishing relationship between RN and strength $\left(f_{c}\right)$ (Figure 6 ). The results of regression analysis conducted on the $\mathrm{RN}$ data and $\mathrm{f}_{\mathrm{c}}$ obtained from the crushing tests indicated that coefficient of correlation was 0.96 , suggesting that there was a strong and positive relationship. Moreover, empirical function betwe en them is shown in Equation 11, having coefficient of determination of about 0.93 . It is possible, therefore, to use this equation to determine compressive strength of the concrete at any age and water-cement ratio within the limit considered in this study. As for other ages or w/c, the equation may be used to give rough estimate of the strength, where preliminary study is required. 


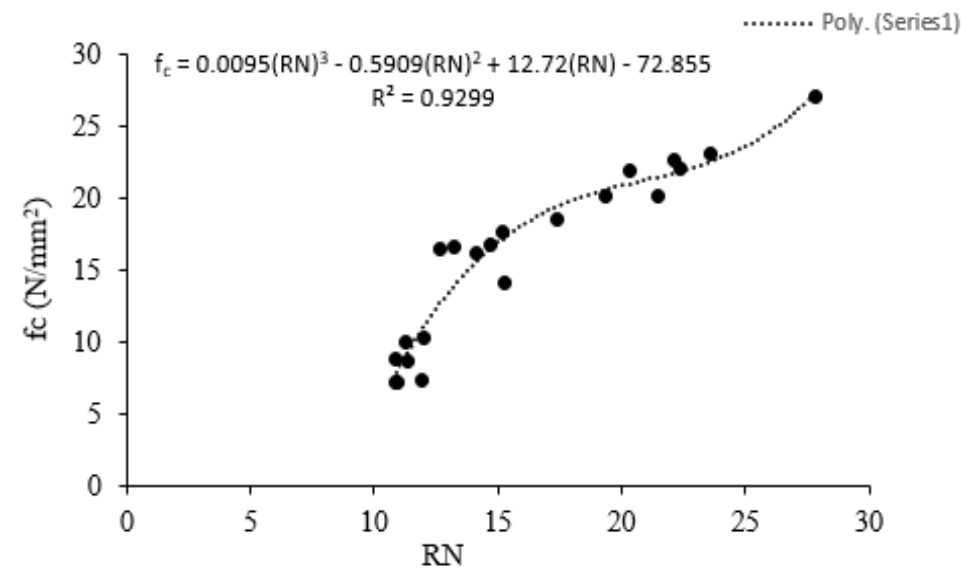

Figure 6 RN versus compressive strength

$$
f_{e}=0.0095(R N)^{3}-0.5909(R N)^{2}+12.72(R N)-72.855 \quad\left(R^{2}=0.9299\right)
$$

\subsection{CONCLUSION}

Schmidt hammer test was conducted on different concrete specimens made from different water-cement ratio at ages 3 , 7 and 28 days. Regression analyses were conducted on the data obtained and the following conclusions were made from the study:

i. Water cement ratio and age had significant effect on the RN of concrete, but admixture dosage did not have influence on the RN.

ii. About $90 \%$ of the values of $\mathrm{RN}$ are influenced by the values of $w / c$ and age of the concrete.

iii. Conversion tables provided by the manufacture could not account for compressive strength of early age concrete that has RN less than 20.

iv. Regression equation to predict compressive strength of the concrete specimen from the RN were established and had about $92 \%$ predictive potential. Thus, the equation could be used to estimate compressive strength of concrete that has RN less than 20.

v. There is need for further study to account for concre te at older ages and effect of direction of application of the $\mathrm{SH}$ on compressive strength.

\section{References}

[1] Malhotra, V. M., \& Carino, N. J. 2004. Handbook on Nondestructive Testing of Concrete. CRC Press.

[2] Zaky, S. 2001. Evaluation of concrete structural members contained different types of coarse aggregate using Schmidt hammer apparatus after 28-day and at later ages. Inter Build.201214.

[3] Woodson, R. D. 2009. Evaluating concrete in concrete structures. Concrete Structures, 6: 3-18. https://doi.org/doi:10.1016/b978-185617-549-4.00002-2

[4] ASTM C805-13. 2013. Standard Test Method for Rebound Number of Hardened Concrete. American Society for Testing and Materials, West Conshohocken, PA.

[5] BS EN 12350-2. 2009. Testing fresh concrete. Slump-test. British Standards Institution.

[6] IS 13311 (Part 2). 2004. Non-Destructive Testing of Concrete Methods of Test. Bureau of Indian Standards, new Delhi.

[7] Sanchez, K., \& Tarranza, N. 2014. Reliability of Rebound Hammer Test in Concrete Compressive Strength Estimation. International Journal of Advances in Agricultural \& Environmental Engineering. 1(2): 198-202.
[8] Rubene, S., \& Vilnitis, M. 2014. Use of the Schmidt Rebound Hammer for Non-Destructive Concrete Structure Testing in Field. Technical Transactions: Civil Engineering. 1-B: 13-19.

[9] Shariati, M., Ramli-Sulong, N. H., Arabnejad, M. M., Shafigh, K. H. P., \& Sinaei, H. 2011. Assessing the strength of reinforced concrete structures through Ultrasonic Pulse Velocity and Schmidt Rebound Hammer tests. Scientific Research and Essays. 6(1): 213-220.

[10] Brozovsky, J. 2012. Implementation of non-destructive impact hammer testing methods in determination of brick strength. Applied Mechanics and Materials. 174-177: 280-285.

[11] Tamil, S. P., Lakshmi, N. P., \& Ramya, G. 2014. Experimental study on concrete using copper slag as replacement material of fie aggregate. Journal of Civil \& Environmental Engineering. 4(5): 1-6.

[12] Cargill, J. S., \& Shakoor, A. 1990. Evaluation of empirical methods for measuring the uniaxial compressive strength of rock. International Journal of Rock Mechanics and Mining Sciences \& Geomechanics Abstracts. 27: 495-503.

[13] Frauenfelder, R., Laustela, M., \& Kääb, A. 2005. Relative age dating of Alpine rock glacier surfaces. Zeitschrift Für Geomorphologie. 49: 145-166.

[14] Amasaki, S. 1991. Estimation of strength of concrete structures by the rebound hammer. CAJ Proc. Cement and Concrete. 45: 345351.

[15] Mitchell, L. J., \& Hoagland, G. G. 1961. Investigation of the Impact Tube Concrete Test Hammer. Highway Research Board.

[16] Grieb, W. 1958. Use of the Swiss Hammer for Estimating the Compressive Strength of Hardened Concrete. FHWA Public Roads

[17] Kolek, J. 1958. An Appreciation of the Schmidt Rebound Hammer. Magazine of Concrete Research. 10(28): 27-36.

[18] Yasar, E., \& Erdogan, Y. 2004. Estimation of rock physicomechanical properties using hardness methods. Engineering Geology. 71: 281-288.

[19] Aydin, A., \& Basu, A. 2005. The Schmidt hammer in rock material characterization. Engineering Geology. 81:1-14.

[20] BS EN 1097-3. 1998. Tests for Mechanical and Physical Properties Of Aggregates. British Standards Institution

[21] Peck, R. B., Hanson, W. E., \& Thornburn, T. H. 1974. Foundation engineering (2nd ed.). John Wiley, New York.

[22] BS EN 12350 2009. Testing of fresh concrete. British Standards Institution.

[23] BS EN 12390-3. 2009. Testing hardened concrete: Compressive strength of test specimens. British Standards Institution.

[24] Kennedy, J. B., \& Neville, A. M. 1986. Basic Statistical Methods for Engineers and Scientists. Donnelley Publishers.

[25] Shetty, M. S. 2005. Concrete Technology: Theory and Practice (Multicolour Revised Ed). S. Chand \& Company Ltd. New Delhi.

[26] Neville, A. M 2005. Properties of Concrete, Pearson Education Limited, UK. 5th Edition.

[27] Newman, J., \& Choo, B. S. 2003. Advanced Concrete Technology Concrete Properties. Butterworth-Heinemann, Elsevier Ltd., England 